\title{
Topographic and morphometric study of the mental foramina of Abaza goats with its clinical implication for regional anaesthesia
}

\author{
S. Dalga \\ Department of Anatomy, Faculty of Veterinary Medicine, Kafkas University, Kars, Turkey \\ [Received: 23 July 2019; Accepted: 23 October 2019]
}

\begin{abstract}
Background: In this study, the topographic and morphometric structure of the mental foramen of both female and male Abaza goats, a domestic goat breed found in Turkey, was examined.

Materials and methods: The mandibles and body weights of 30 adult Abaza goats, both female and male, were used. The goats were obtained during the sale of the Abaza goat herd sacrificial and forbearance. The mandibles were separated from the head and the skin, muscles and ligaments were cleaned and the mandibles were left to dry by standard technique. Various measurements were carried out on the mandible in accordance with relevant studies in the literature. Results and Conlusions: The mental foramina of the goats were round and oval and the mental foramina on one mandible were not necessarily of the same shape. In addition, the number of mental foramina, which differed between goats, was observed to be two in most goats. The distance between the mental foramen and the ventral edge of the mandible was $0.88 \pm 0.15 \mathrm{~cm}$. The distance between the first premolar teeth and the mental foramen was found to be $1.59 \pm 0.13 \mathrm{~cm}$. The distance between the mental foramen and the lateral incisor was $1.85 \pm 0.39 \mathrm{~cm}$. The distance between the caudal edge of the ramus mandibulae and the mental foramen was calculated as $12.38 \pm 1.52 \mathrm{~cm}$. (Folia Morphol 2020; 79, 3: 576-579)
\end{abstract}

Key words: Abaza goat, anatomy, mental foramen

\section{INTRODUCTION}

Abaza goats, which are bred in the province of Artvin in Turkey, are generally bronze, white, black and brown. Their mouths, horns, legs and the areas around their eyes are black. In terms of their body structure, they are thin and slender and likened to the gazelle [2].

Morphometry is a research method that allows the statistical analysis of the width, length or angle measurements between two specific points numerically or graphically [18]. In the literature $[1,7,8,16]$, various morphometric studies have been conducted on the mandibles of different animal species using different methods.

It has been previously reported that the mental artery and mental nerve pass from the mental foramen $[4,5]$. In an emergency situation that requires surgical intervention, it is very easy to locate this region as a topographical for quick and easy anaesthesia to block the mental nerve. Knowing the topographic and morphometric anatomy of the mental foramen provides simplicity in veterinary surgery during an emergency $[3,15]$.

In the literature, morphometric analyses have been performed in different countries on different 


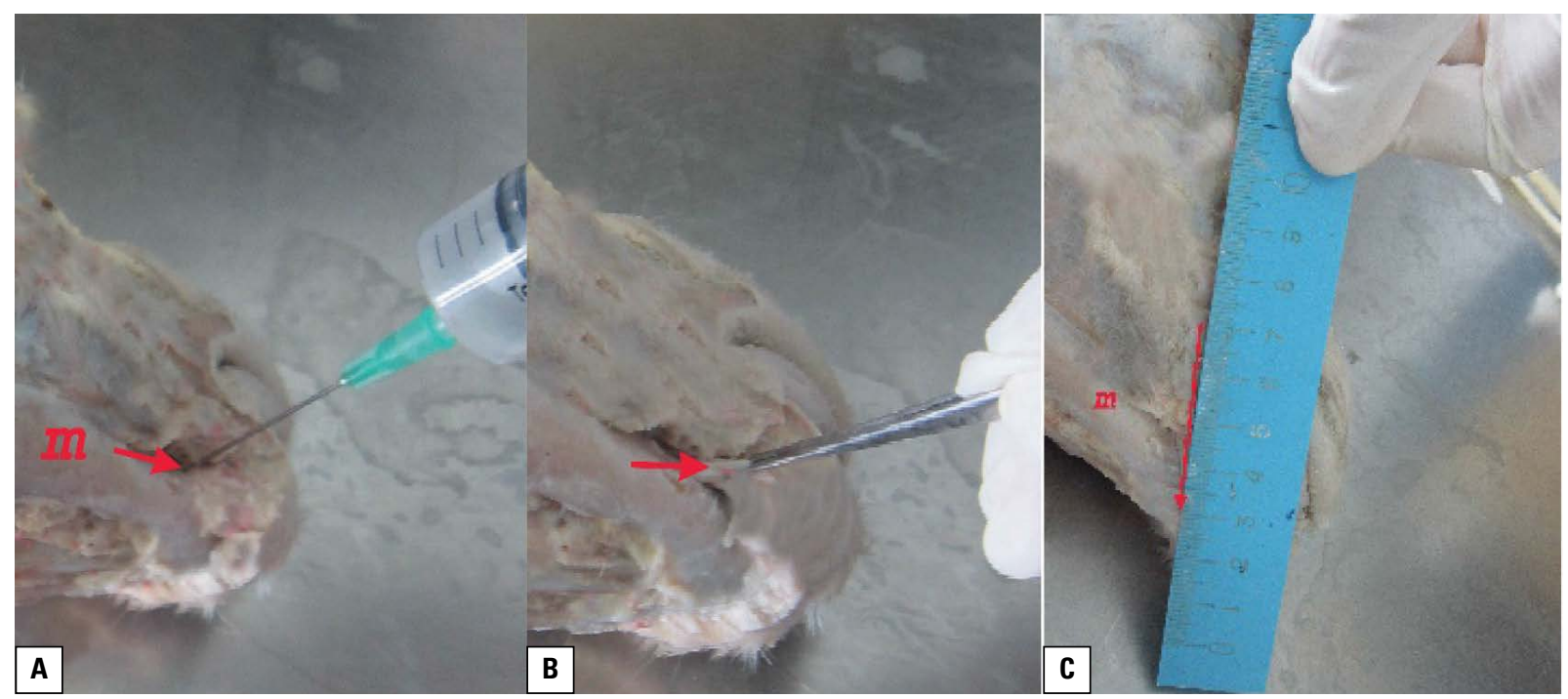

Figure 1. A. Mental foramen; B. Mental nerve; C. Distance between the mental foramen and commisura labiorum.

goat breeds $[6,10,13,14]$. However, very few studies observed that mental foramen is on topographic and morphometric structure $[17,19]$.

\section{MATERIALS AND METHODS}

In this study, mandibles of 30 Abaza goats, both female and male, were used. The mandibles were collected along with their skulls during the sacrificial slaughtering of the Abaza goats of the animal farm of the Kafkas University's Veterinary Faculty. First, the mental foramen was removed from the skulls along with the mental nerve. The muscles and ligaments were then separated from the mandibles. The mandibles were dried using standard bone maceration technique $[10,11]$. Then, in accordance with the literature, measurements were carried out with an electronic calliper from the points mentioned below:

- the mental foramina were identified in various shapes, size and directions at the lateral aspect of the rostral part of each mandible;

- the distance from the lip commissure to the mental foramen was measured and recorded;

- the distance from the base of the mandible (ventral border of the mandible) to the mental foramen was measured and recorded;

- the distance from the lateral alveolar border of the first premolar tooth to the mental foramen was measured and recorded;

- the distance from the lateral extent of the alveolar root of the lower incisor to the mental foramen was measured and recorded;
- the distance from the caudal border of the mandibular to the mental foramen was measured and recorded.

The mean values of all measurements with standard deviations were evaluated in SPSS Statistics 20.0.

\section{RESULTS}

The mental foramen and mental nerve on the lateral face of the mandible are shown in Figure 1. It was observed that the mental foramina in Abaza goats were quite different. Mental foramina of different structures were observed between the bilateral faces of the same mandible. It was determined that two of the goats had two mental foramina on each side of their mandible. Three of the goats had two mental foramina on one side of the mandible and only one mental foramen on the other side. There were four mandibles with an oval shaped mental foramen, while three of the mental foramens were round. In addition, there was a protrusion extending from the middle of the mental foramen of three mandibles (Fig. 2).

The measurement points taken to determine the topographic and morphometric location of the mental foramina are shown in Figure 3. The average and standard deviation values of the values taken from these measurement points are given in Table 1 .

\section{DISCUSSION}

Figure 2 shows the mental foramen in different shapes and sizes. The results of this study are similar to those of Monfared et al. [13], Goodarzi and Hosseini [6], Kataba et al. [10] and Poddar et al. [17] in the literature. 

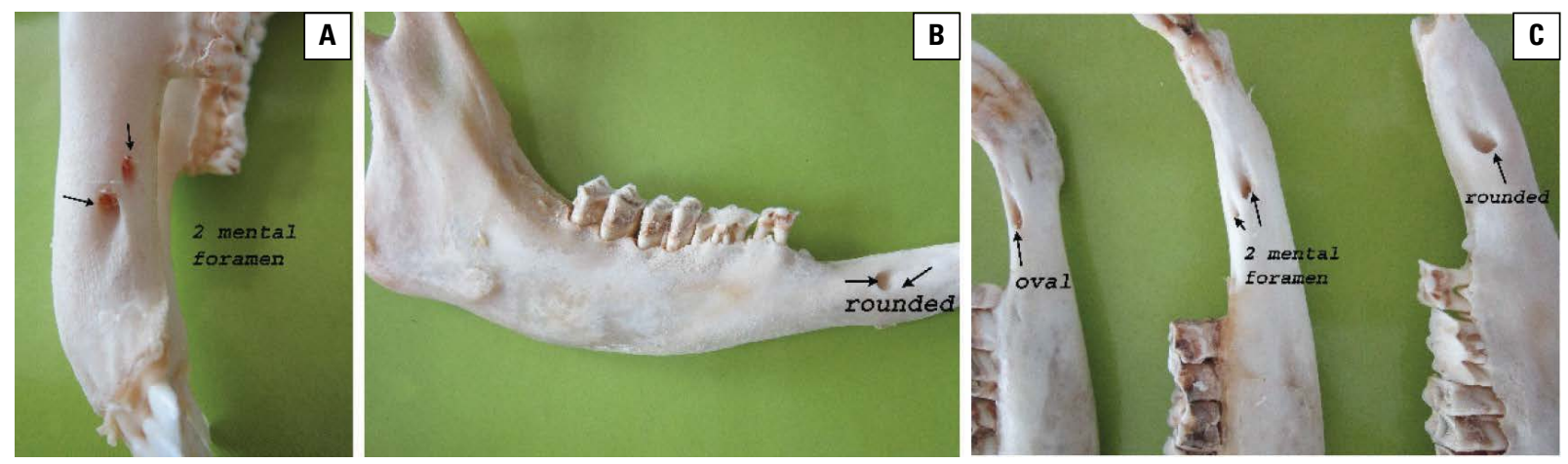

Figure 2. A. Two mental foramina; B. Round shaped mental foramen; C. Oval shaped mental foramen.
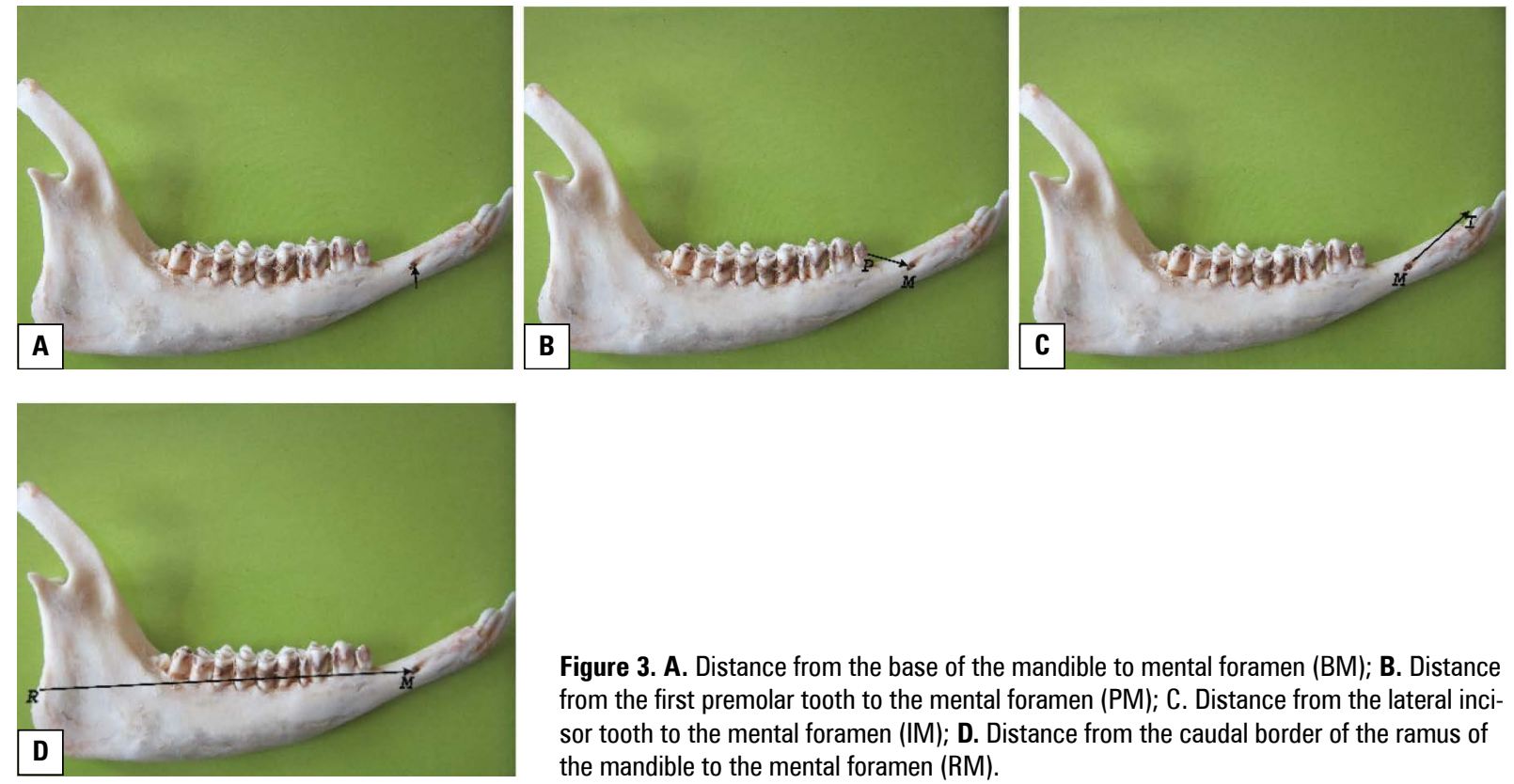

Figure 3. A. Distance from the base of the mandible to mental foramen (BM); B. Distance from the first premolar tooth to the mental foramen (PM); C. Distance from the lateral incisor tooth to the mental foramen (IM); D. Distance from the caudal border of the ramus of the mandible to the mental foramen (RM).

Table 1. Morphometric anatomy of the mental foramen of the mandible of the Abaza goats

\begin{tabular}{lcc}
\hline Parameter & $\begin{array}{c}\text { Mean } \\
{[\mathbf{c m}]}\end{array}$ & $\begin{array}{c}\text { Standard } \\
\text { deviation [cm] }\end{array}$ \\
\hline $\begin{array}{l}\text { Distance from the lip commissure to the } \\
\text { mental foramen }\end{array}$ & 3.12 & 0.9 \\
$\begin{array}{l}\text { Distance from the base of the mandible to } \\
\text { the mental foramen }\end{array}$ & 0.88 & 0.15 \\
$\begin{array}{l}\text { Distance from the first premolar tooth to } \\
\text { the mental foramen }\end{array}$ & 1.59 & 0.13 \\
$\begin{array}{l}\text { Distance from the lateral incisor tooth to } \\
\text { the mental foramen }\end{array}$ & 1.85 & 0.39 \\
$\begin{array}{l}\text { Distance from the caudal border of the } \\
\text { ramus of the mandible to the mental } \\
\text { foramen }\end{array}$ & 12.38 & 1.52 \\
\hline
\end{tabular}

In the present study, the distance from the mental foramen to the ventral edge of the mandible in the
Abaza goats was measured as $0.88 \pm 0.15 \mathrm{~cm}$. This distance was determined to be $0.77 \pm 0.04$ by Poddar et al. [17], $0.70 \pm 0.18 \mathrm{~cm}$ by Mohamed et al. [12] and $2.35 \pm 0.26 \mathrm{~cm}$ by Kataba et al. [10].

The distance from the first premolar teeth to the mental foramen was found to be $1.59 \pm 0.13 \mathrm{~cm}$ in the present study. This distance was found to be $1.46 \pm 0.09 \mathrm{~cm}$ by Mohamed et al. [12] and $2.25 \pm$ $\pm 0.38 \mathrm{~cm}$ by Poddar et al. [17]. As a result, it is suggested that the mental foramen can be palpated at the distance of the first premolar tooth $(1.59 \pm 0.13 \mathrm{~cm})$ in the Abaza goats.

The present study determined the distance between the mental foramen and the lateral incisor tooth to be $1.85 \pm 0.39$ in the Abaza goats. This distance was reported to be $2.01 \pm 0.05 \mathrm{~cm}$ by Poddar et al. [17], $2.11 \pm 0.17$ by Uddin et al. [19], $2.25 \pm$ $\pm 0.31 \mathrm{~cm}$ by Mohamed et al. [12], $1.56 \pm 0.22 \mathrm{~cm}$ 
Table 2. Comparison of the results of similar parameters for Abaza goats and other small ruminants

\begin{tabular}{|c|c|c|c|c|c|}
\hline Parameter & $\begin{array}{c}\text { Distance from the } \\
\text { lip commissure to } \\
\text { the mental fora- } \\
\text { men [cm] }\end{array}$ & $\begin{array}{l}\text { Distance from the } \\
\text { base of the mandi- } \\
\text { ble to the mental } \\
\text { foramen }[\mathrm{cm}]\end{array}$ & $\begin{array}{l}\text { Distance from } \\
\text { the first premolar } \\
\text { tooth to the men- } \\
\text { tal foramen [cm] }\end{array}$ & $\begin{array}{l}\text { Distance from } \\
\text { the lateral incisor } \\
\text { tooth to the men- } \\
\text { tal foramen [cm] }\end{array}$ & $\begin{array}{l}\text { Distance from the } \\
\text { caudal border of the } \\
\text { ramus of the man- } \\
\text { dible to the mental } \\
\text { foramen [cm] }\end{array}$ \\
\hline Black Bengal goat (Uddin et al. [19]) & & & & $2.11 \pm 0.17$ & $11.69 \pm 0.40$ \\
\hline Mehreban sheep & & & & & $13.74 \pm 0.18$ \\
\hline Barbados Black Belly sheep & & $0.70 \pm 0.18$ & $2.25 \pm 0.38$ & $2.25 \pm 0.31$ & $15.23 \pm 1.46$ \\
\hline Gwembe Valley Dwarf goat & & $2.35 \pm 0.26$ & & $1.58 \pm 0.19$ & $9.26 \pm 0.49$ \\
\hline Black Bengal goat (Poddar et al. [17]) & $2.37 \pm 0.09$ & $0.77 \pm 0.04$ & $1.46 \pm 0.09$ & $2.01 \pm 0.05$ & $11.81 \pm 0.89$ \\
\hline West African Dwarf goat & & & & $1.56 \pm 0.22$ & \\
\hline Abaza goat & $3.12 \pm 0.9$ & $0.88 \pm 0.15$ & $1.59 \pm 0.13$ & $1.85 \pm 0.39$ & $12.38 \pm 1.52$ \\
\hline
\end{tabular}

by Olopade and Onwuka [14] and $1.58 \pm 0.19 \mathrm{~cm}$ by Kataba et al. [10].

The distance from the caudal edge of the ramus mandible to the mental foramen in the Abaza goats was found as $12.38 \pm 1.52 \mathrm{~cm}$ in the present study. This distance was reported by Poddar et al. [17] as $11.8 \pm 0.89$, Uddin et al. [19] as $11.69 \pm 0.4 \mathrm{~cm}$ and Kataba et al. [10] as $9.26 \pm 0.49 \mathrm{~cm}$. It was observed that this distance was higher in the present study compared to those reported in the literature. This statement excludes the results of Karimi et al. [9] who found this value to be $13.74 \pm 0.18 \mathrm{~cm}$ for Mehreban sheep and Mohamed et al. [12] who found it to be $15.23 \pm 1.46 \mathrm{~cm}$ (Table 2 ).

\section{CONCLUSIONS}

Meaningful the topographic and morphometric anatomy of the mental foramen is considered to be beneficial for any situation where urgent surgical intervention is required.

\section{REFERENCES}

1. Akbulut $Y$, Demiraslan $Y$, Gürbüz I, et al. Yeni Zelanda Tavşanı (Oryctolaguscuniculus L.)'ında cinsiyet faktörünün mandibula morfometrisine etkisi. Fırat Üniv Sağl Bil Vet Derg. 2014; 28: 15-18.

2. Batu S. Türkiye Keçi Irkları. Ankara Üniversitesi Veteriner Fakültesi Yayınları, Ankara 1951.

3. Dyce KM, Sack WO, Wensing CJG. Textbook of Veterinary Anatomy, 3rd ed. WB Saunders, Philadelphia, USA 2002.

4. Getty R. Session and Grossman's The Anatomy of the Domestic Animals, 2nd ed. Vol. 1. WB Saunders, Philadelphia, USA 1975.

5. Ghosh RK. Primary veterinary anatomy, 5th ed. Current books International, Kolkata, India 2012.

6. Goodarzi N, Hoseini TJ. Morphometric characteristics of the maxillofacial and mandibular regions of markhoz goat breed and its clinical value for regional anaesthesia in western iran. Global Veterinaria. 2013; 11(1): 107-111.
7. Gurbuz I, Demiraslan Y, Gulbaz F, et al. Morphometric features of the mandible of Malakan Horse according to gender. Eurasian J Vet Scien. 2016; 32(3): 136-136, doi: 10.15312/eurasianjvetsci.2016318390.

8. Ince Gezer N, Pazvant G. Morphometry of the Mandible in rats (wistar Albino). J Fac Vet Med İstanbul Univ. 2010; 36(1): 51-56.

9. Karimi I, Hadipour MM, Nikbakht P, et al. The Lower Jawbone of Mehraban Sheep: A descriptive morphometric approach. World's Vet J. 2012; 2(4): 57-60.

10. Kataba A, Mwaanga ES, Simukoko H, et al. Clinical anatomy of the head Region of Gwembe Valley dwarf goat in Zambia. Int J Vet Scien. 2014; 3(3): 142-146.

11. Merai MK. Anatomical museum preparations of the skeleton and respiratory organs of some domestic animals. MVSc, Faculty of Veterinary Medicine, Beni-Suef University, Egypt 2012.

12. Mohamed R, Drisco M, Mootoo N. Clinical Anatomy of the skull of the Barbados Black Belly Sheep in Trinidad. Int J Curr Res Med Scien. 2016; 2(8): 8-19.

13. Monfared AL, Naji H, Sheibani MT. Applied anatomy of the head region of the Iranian Native goats (Capra hircus). Global Vet. 2013; 10(1): 60-64.

14. Olopade JO, Onwuka SK. An osteometric study of the skull of the West African Dwarf Goat fromthe South Eastern Nigeria. II: Mandibular and Maxillofacial features. Nigerian Vet J. 2007; 27(2): 66-70, doi: 10.4314/nvj.v27i2.3517.

15. Ommer PA, Harshan KR. Applied anatomy of domestic animals. 1st ed. Jaypee Brother's Medical Publisher, India 1995.

16. Onar V, Kahvecioğlu O, Mutuş R, et al. Alman kurt köpeklerinde mandibula'nın morfometrik analizi. Turk J Vet Anim Sci. 1999; 23: 329-334.

17. Poddar S, Faruq AA, Dey T, et al. Topographic and morphometric anatomy of mental foramen of black bengal goat (capra hircus) in Bangladesh with its clinical implication for regional anesthesia. Int J Zoo Animal Biol. 2018; 1(1), doi: 10.23880/izab-16000102.

18. Rohlf FJ, Marcus L. A revolution morphometrics. Trends Ecol Evol. 1993; 8(4): 129-132, doi: 10.1016/01695347(93)90024-j.

19. Uddin M, Ahmed S, Islam K, et al. Clinical Anatomy of the Head Region of the Black Bengal Goat in Bangladesh. Int J Morphol. 2009; 27(4), doi: 10.4067/s071795022009000400048. 